\title{
The health Sector Between Innovation and Organizational Performance: Applied Research in Moroccan Hospitals
}

\author{
Abderrahmane Ouddasser, Anass Mellouki, Yassine Belyagou*, Kamal Yazzif
}

University Sidi Mohamed Ben Abdellah, Fez, 30000, Morocco

\begin{tabular}{l} 
A R T I C L E I N F O \\
\hline Article history: \\
Received: 25 March, 2021 \\
Accepted: 02 May, 2021 \\
Online: 28 May, 2021 \\
\hline Keywords: \\
Technological innovation \\
Medical innovation \\
Organizational performance \\
Health establishments
\end{tabular}

\section{Introduction}

If innovation is a concept widely used nowadays, it nevertheless refers to evolving definitions and plural approaches. Today, innovation is at the center of all concerns, since it consists of proposing new solutions and contributing to the success of the organization. Joseph Schumpeter an Austrian economist, proposed an epistemological reflection on the concept of innovation, showing that the types of innovation are appreciable elements to know the stages of growth [1].

Today the field of health is strongly linked to the ideology of progress and precisely to innovation. Although the subject of healthcare innovation is of striking topicality, it is, therefore, necessary to better understand the place occupied by this paradigm, which generally requires the active involvement of stakeholders in any strategic hospital decision, in the ultimate objective is to provide quality services for the benefit of users. The literature also reveals a space of conformity between the user and the hospital, and that this user must be considered as an actor in the recognition and creation of the value of healthcare establishments [2]. Let us note here that innovation is a priority

*Corresponding Author: Yassine Belyagou : yassine.belyagou@usmba.ac.ma for any hospital organization whose objective is to face current challenges and an uncertain future.

Our paper will therefore look at the study of innovation through its various forms such as organizational innovation, technological innovation, and medical innovation to improve the performance of hospital activities. The central question that challenges us is the following: What role do organizational, technological, and medical innovation play in improving the organizational performance of healthcare establishments?

This present paper is composed of three essential parts, first, we devote to explaining innovation in its organizational form, then, we will propose to apprehend technological innovation, while the third part, will give place to a reading of medical innovation and its impact on organizational performance within healthcare establishments. Finally, we will carry out an empirical study that serves to measure the variables used and to test all the hypotheses from the literature.

This paper aims to study the classification of data within hospitals, then, we will study the contribution of pricing in improving the financial performance of healthcare establishments, and finally, we will carry out an empirical study. 
Making it possible to measure and test all the hypotheses constituting the subject of our research question.

\section{Literature review}

Given the evolution of the health sector in recent years, it is clear that there are still dysfunctions in terms of innovation, as well as the good management of relations between health professionals. With this in mind, if we understand the perceptions and perspectives of healthcare professionals, it will lead to profound changes going forward. It is certainly possible to envisage a new space dedicated to completely modifying the traditional working methods in all sectors, more particularly at the level of the health system. Among these transformations, we retain here that the patient is a fundamental partner in any process of change. It is important to realize that the change can be envisaged primarily to understand that the organization is a space of exchange of ideas and values between the actors who think of remedying the problems of the sick people but on condition of leaving innovative traceability among all stakeholders [3].

In 2000, Dodgson and Hinze defined innovation as "the scientific, technological, organizational, financial activities leading to the introduction of a new product, process or a new organization or even the improvement of these when they already exist" [4]. The most commonly accepted idea about innovation is that it allows for the creation of a panoply of legislative reforms and thus allows for significant experiences in terms of sustainability and coordination [5].

\subsection{Organizational innovation: a considerable evolution within healthcare establishments}

Today, health establishments are very aware of strengthening the capacity of resources to face multiple obstacles, moreover, these establishments aim to provide care but also aim to promote innovation and manage risks [6]. Simply, human, technical and financial resources thus make it possible to increase the performance of hospitals [7]. It is necessary to understand that taking into account different tactics in favor of funds, therefore allow building a flexible, harmonious environment between the hospital, and its users. In recent years, organizational innovation has been considered to be a powerful lever for development, and sustainability for the health system, since it is currently suffering from a multitude of upheavals and constraints that hamper its development.

Currently, the health organization is working to promote the implementation of innovation projects in the organizational, technological, financial, and even institutional order. Also, hospitals must promote and value innovation from implementation through adoption and ownership across the industry to provide better performing and high-quality services for the benefit of patients. That said, several conclusions can be presented as follows :

- The collaborative work of all healthcare stakeholders (doctor, administrator, patient, etc.) in the adoption, appropriation and dissemination of innovation.

- Develop the creation and strengthening of innovation based on the technological aspect through fundamental scientific research, thus promoting public and private funding for research and development, and also creating public-private partnerships and knowledge exchange.

- Involve the perception of patients in the decision-making of any innovation.

- Highlight the advantages and benefits expected by the patients in order to recommend more adequate strategies in the realization.

- The establishment of training sessions for health professionals (administrators, executives, etc.) as well as the establishment of a control service.

Finally, this organizational innovation aims to increase transparency and improve the consistency of hospital actions carried out by healthcare professionals with the main objective of strengthening the patient-hospital relationship, but also strengthening the control of power over the hospital executive, and also to modernize health care facilities to provide quality and high-level services. It should be noted that organizational or even managerial innovation can generate significant results within specific timeframes. The advantages of innovation are also based on the design of new products as well as an optimization in terms of working methods, it should be noted that innovation makes it possible to change the subjective value of agents to an objective value allowing to increase well-being.

Given the results of the literature review, we underline that the first hypothesis essentially concerns the role that organizational innovation can play in the improvement of hospital structures.

H.1. Organizational innovation impacts organizational performance within healthcare facilities.

\subsection{Technological innovation in health: a necessity for the future}

The Today, the healthcare world faces several simultaneous challenges that are quite different from those that healthcare facilities usually face. The technology promised to reduce economic costs and promote a more sustainable and efficient health system [8]. In this regard, access to health information now transcends all geographic boundaries. The literature points out that public and private organizations are faced with a variety of issues that hinder their advancement, which prompts them to put in place innovative and highly developed strategies to deal with them. These strategies are technological innovations, especially when referring to the introduction of new technology into the organizational process or the launch of a new service. Whatever our attachment to the concept of technological innovation, we can deduce that it is one of the main windows of opening and modernization of hospital management practices. Otherwise, both tangible and intangible innovation can build rigorous models for maintaining well-being [9]. Although others like the OECD (2005) define innovation as: “ [...] Implementation of a new or significantly improved product (good or service) or process, of a new marketing method or of a new organizational method in the practices of the company, the organization of the workplace or external relations" [10].

Taking the example of the Organization for Economic Cooperation and Development, which emphasizes four types of innovation, namely: Innovation mainly concerns products and still processes, let us also add other types of innovation. 
Innovations that influence marketing and internal and external communication methods, and ultimately organizational innovation and technological innovation. In the same context, notable advances have been made in the area of innovation, highlighting all types of innovations in the field of health.

Digital technologies have become omnipresent in professional activities [11], their deployment leads to profound changes in working methods, affecting the heart of activities and also affecting those carried out at its periphery on more relational and organizational dimensions, and managerial [12]. They also modify those that take place outside the traditional boundaries of the company, with teleworking [13]. Indeed, digital technology is an "accelerator of progress" in the field of medical research, it still makes it possible to study the evolution of a disease in many patients and further allows treatments to be better adapted to each individual particular case.

Given the results of the literature review, we underline that the second hypothesis essentially relates to the role that technology can play in improving hospital practices.

H.2. Technological innovation impacts organizational performance within healthcare establishments.

\subsection{Medical innovation: a priority within healthcare establishments}

The best way to deal with problems is to accept innovation as an underlying element in all actions. It is important to note that medical innovation has been able to generate several benefits, although these main missions continue to advance [14]. We underline that this type of innovation can take several forms, particularly when we are talking about innovation in pharmaceutical products (new drugs) or an invisible innovation that serves to renew care practices and therapeutic protocols in favor of patients users [15]. Also, a movement in medicine has emerged, today we can speak of collaborative medicine, personalized or even sustainable in terms of actions. But what gives birth to this sector is the aspect of innovation as well as the technology dedicated to this field. Of course, the patient and his family seek to benefit from agile information and quality service that will ensure their well-being.

Despite the advances made in medical innovation in the health sector, this innovation consists of restructuring traditional working methods, thus forging intimate links between health professionals and their patients. It is remarkable to indicate that this innovation occupies a preponderant place in the improvement of the care, in the progress of pharmaceutical products (drugs) as well as in the improvement of surgical techniques which have a positive impact on the speed of treatment the length of hospitalization, the minimization of stay, and the performance in terms of interventional radiology which calls into question the distribution of care between professionals. This innovation fundamentally changes the digital tools connected to the monitoring and treatment of medical cases for the benefit of patients. Moreover, the latter has a significant impact on the methods of care, on the duration of hospitalization (the stay), and also on the level of all the information related to the hospital [16].

However, to speak of the efforts of medical innovation, it is first to give importance to the institutional framework which plays in any hospital activity and thus supporting an improvement in the conditions. On the strength of its strengths, medical innovation has thus consolidated its position by creating a change in methods for economic practices. Several factors can push healthcare institutions to think globally towards the optics of medical innovation. That said, medical innovation, therefore, represents the progress expected from the healthcare establishment; it generally involves the introduction of new instruments for modernizing hospital practices as well as an improvement in priority strategies relating to patient pathology [17].

Given the results of the literature review, we underline that the second hypothesis essentially relates to the role that technology can play in improving hospital practices.

H.3. Medical innovation impacts organizational performance within healthcare establishments

\section{Methodology}

In this part, we are interested in explaining only our research approach which focuses mainly on our epistemological and methodological positioning, then, we will focus on operationalizing the dimensions of the independent variable and the dependent variable.

\subsection{The research approaches}

Following an in-depth reading of the literature on the field of innovation and the performance of hospital organizations, this work will attempt to answer the question of our research and to test the relationships that may exist between the different variables, we let's talk in particular about our research hypotheses.

This relationship is broadly part of the cause and effect between the independent variable (innovation) and the dependent variable (organizational performance). On the one hand, we will rely on carrying out an exploratory factor analysis to test the reliability and internal consistency of the measurement scales using the SPSS software, on the other hand, we will attempt to carry out the second analysis, said, confirmatory factor analysis which will lead us to confirm or refute all the hypotheses from our literature [18]. This logic is generally part of a positivist paradigm with a hypothetico-deductive approach and will be structured around a quantitative methodology [19].

\subsection{Operationalization of the independent variable}

The operationalization of the variables of our research work is a fundamental step insofar as it makes it possible to make the variables more concrete and readable in our field of research. Besides, this step will allow us to easily understand the different concepts used while drawing on previous studies thus promoting several clarifications around innovation and organizational performance.

Moreover, for the independent variable, we opted for the work of [20], [4] as well as the work carried out by [21]. These various previous works have led us to understand that innovation with its various forms, both organizational, technological, and medical, is intended to make the hospital context more efficient and adapted to the expectations of the population. 
Clearly and precisely, it should be emphasized that innovation is a crucial element in the improvement of any hospital activity, that said, health establishments must strongly commit to the path of organizational innovation that is mainly based on the restructuring of working methods and the appropriation of a management style adapted to the hospital context. Likewise, technological innovation allows healthcare establishments to subscribe to the logic of digitizing the methods practiced within medico-technical services. Finally, the investment in medical innovation can further modify treatment protocols and will still allow the hospital's stocks of pharmaceutical products to be perfectly managed.

These three types of innovation are essential for the sustainability of hospital activities and make it possible to guarantee efficiency and high quality in terms of care and safety for patients and users. Table 1 clearly shows the three dimensions of the independent variables.

Table 1: Operationalization of the independent variable

\begin{tabular}{|c|c|c|c|}
\hline The independ & variable mea & ement scales & References \\
\hline $\begin{array}{c}\text { Organizational } \\
\text { innovation }\end{array}$ & $\begin{array}{l}\text { Technological } \\
\text { innovation }\end{array}$ & $\begin{array}{c}\text { Medical } \\
\text { innovation }\end{array}$ & \multirow{5}{*}{$\begin{array}{c}\text { Cloutier (2003) } \\
\text { Dodgson et } \\
\text { Mark (2000) } \\
\text { Eunika } \\
\text { Mercier- } \\
\text { Laurent (2008) } \\
\text { [22] }\end{array}$} \\
\hline $\begin{array}{l}\text { continuous } \\
\text { training }\end{array}$ & $\begin{array}{l}\text { The proper } \\
\text { use of connected } \\
\text { tools }\end{array}$ & $\begin{array}{c}\text { Drug } \\
\text { inventory } \\
\text { management }\end{array}$ & \\
\hline $\begin{array}{r}\text { Staff } \\
\text { motivation }\end{array}$ & $\begin{array}{c}\text { Integration of } \\
\text { the information } \\
\text { system }\end{array}$ & $\begin{array}{c}\text { Improved } \\
\text { treatment } \\
\text { protocol }\end{array}$ & \\
\hline $\begin{array}{l}\text { Valuation of } \\
\text { skills }\end{array}$ & $\begin{array}{c}\text { Appropriation } \\
\text { of management } \\
\text { tools }\end{array}$ & $\begin{array}{r}\text { Diagnostic } \\
\text { and therapeutic } \\
\text { strategies }\end{array}$ & \\
\hline $\begin{array}{c}\text { Career } \\
\text { Management }\end{array}$ & $\begin{array}{c}\text { Research and } \\
\text { development }\end{array}$ & $\begin{array}{c}\text { Digital } \\
\text { pharmacy }\end{array}$ & \\
\hline
\end{tabular}

\subsection{Operationalization of the dependent variable}

For the dependent variable, we opted for the work of [23], [24] as well as the work carried out by [25], [26]. These various research works have enabled us to understand that organizational performance is a major concern for each healthcare establishment. Let us note here that the organizational performance within hospitals resides strongly on the sustainability and sustainability of health activities, in the same way, it depends more and more on providing quality care and services in favor of users, it also includes being part of the logic of efficiency to make the image of the healthcare establishment more attractive to patients.

Generally speaking, the inclusion of the health establishment in the perspective of organizational performance, therefore, makes it possible to promote and strengthen the relationship between the hospital and the patient, thus increasing the productivity of the staff care and services.

We emphasize that performance within a hospital is a major concern insofar as it enables managerial and hospital practices being changed, the objective of which is to provide care as quickly as possible. Specifically, we emphasize that quality will strengthen the interpersonal relationship and forge strong links between hospital and user [27], [28]. Table 2 clearly shows the three dimensions of the dependent variables.

Table 2: Operationalization of the dependent variable

The dependent variable measurement scales

References

\begin{tabular}{|c|c|c|c|}
\hline Sustainability & Efficiency & Quality & Shortell, \\
\hline Adaptation & Achievement of goals & Yield & $\begin{array}{l}\text { Bennett, et } \\
\text { Byck (1998) }\end{array}$ \\
\hline Recognition & Productivity & User satisfaction & Piña-Garza et \\
\hline $\begin{array}{c}\text { Knowledge } \\
\text { sharing }\end{array}$ & Work organization & Accessibility & $\begin{array}{c}\text { Sicotte and } \\
\text { al., (1999) }\end{array}$ \\
\hline
\end{tabular}

\section{Analysis and discussion of the results}

In the following paragraphs, we will rely on carrying out a descriptive analysis of our sample, then we will move on to exploratory factor analysis, and finally, confirmatory factor analysis will be carried out to test our developed hypotheses.

It is important to give an outline presentation of the University Hospital Center in Morocco, in particular of the Fez Meknes region which is an integral part of our study. University Hospital Centers are understood to be public establishments with legal personality and financial autonomy. They play a capital role in the care of our national health system, they perform a variety of missions and are, moreover, centers of excellence in the provision of cutting-edge and high-tech care.

Our questionnaire is based beforehand on introducing simple and precise questions relating to the respondent's profile, then questions related to their professional context, and finally, a set of very relevant questions were addressed, the objective of which is to better understand our problem research.

As part of this empirical process, we will take into consideration the descriptive parameters of our sample of the Hospital - University Hassan II - Fez in Morocco knowing that 215 questionnaires were distributed, 167 questionnaires were returned completed, a response rate by $77.7 \%$.

\subsection{Collection of data}

Before beginning the evaluation of the measurement scales and the test of the hypotheses, we will first present Center Hospital - Hassan II of Fez, Morocco, and a descriptive analysis of the sample.

\section{Descriptive data analysis}

Before proceeding with the development and analysis of the responses, it is necessary to first describe our sample as well as the respondents who will contribute to the success of this research work. Moreover, our respondents are generally health professionals whose function is to ensure the sustainability of the health establishment as well as to meet the expectations of the population in terms of care, and services. The distribution of our sample is generally oriented towards the description by gender, age, profile, a number of years of experience. Table 3 below illustrates all the responses received by health professionals.

\section{The distribution of respondents}

Before proceeding with the development of the analysis of the responses, it is necessary to first describe our sample as well as the respondents who will contribute to the success of this research work. Moreover, our respondents are generally health professionals whose function is to ensure the sustainability of the health establishment and to meet the expectations of the 
population in terms of care and services. The distribution of our sample is generally oriented towards the description by sex, age, profile, number of years of experience.

\section{$>$ By gender}

More than half of the respondents to the questionnaire sent to health professionals are men $(55.1 \%)$. Women only represent $44.9 \%$ of respondents.

\section{$>$ According to age}

Professionals aged between 36 and 44 and those aged between 45 and 54 are the players who have shown more involvement and profit-sharing in our problem and represent respectively $28.7 \%$ and $22.2 \%$ of the total number of respondents. On the other hand, respondents aged over 55 represent only $13.8 \%$. While healthcare professionals aged 27 and 35, and 18 and 26 , respectively, only represent a response rate of $19.1 \%$ and $16.1 \%$

\section{$>$ According to years of experience}

We find that the majority of responses were conducted by respondents with more than 7 years of experience with a rate of $31.1 \%$. So, for people with experience between 5 and 7 years and between 3 and 5 years only represent $29.3 \%$ and $22.2 \%$ respectively. In the end, health professionals who have experience between 1 and 3 years only represent $17.4 \%$ of the responses.

\section{$>$ According to the position held}

Respondents exercising the administration service accounted for $31.7 \%$ of the responses. While doctors and technicians represent $28.7 \%$ and $16.2 \%$ respectively. For the case of nurses and pharmacists, represent only $13.1 \%$ and $10.2 \%$.

Table 3: Description of our sample

\begin{tabular}{|c|c|c|c|}
\hline $\begin{array}{c}\text { Categorical } \\
\text { classification }\end{array}$ & Membership & Frequency & $\%$ \\
\hline \multirow{2}{*}{ Gender } & Female & 64 & 44,8 \\
\hline & Male & 79 & 55,2 \\
\hline \multirow{5}{*}{$\begin{array}{c}\text { Professional } \\
\text { category }\end{array}$} & Administrator & 48 & 33,6 \\
\hline & Doctor & 39 & 27,2 \\
\hline & Male nurse & 19 & 13,2 \\
\hline & Technician & 17 & 11,9 \\
\hline & Pharmacist & 20 & 14 \\
\hline \multirow{5}{*}{ Age } & $18-26$ & 11 & 7,7 \\
\hline & $27-35$ & 18 & 12,6 \\
\hline & $36-44$ & 45 & 31,4 \\
\hline & $45-54$ & 42 & 29,3 \\
\hline & 55 and over & 27 & 18,9 \\
\hline $\begin{array}{l}\text { Region (Hassan } \\
\text { II University } \\
\text { Hospital Center } \\
\text { - Fez) } \\
\end{array}$ & Fez-Meknes & 143 & 100 \\
\hline \multirow{4}{*}{$\begin{array}{l}\text { Number of } \\
\text { years of } \\
\text { experience }\end{array}$} & From 1 to 3 years & 20 & 14 \\
\hline & 3 to 5 years old & 29 & 20,2 \\
\hline & $\begin{array}{l}\text { From } 5 \text { to } 7 \text { years } \\
\text { old }\end{array}$ & 55 & 38,4 \\
\hline & $\begin{array}{l}\text { From } 7 \text { years to } \\
\text { older }\end{array}$ & 39 & 27,3 \\
\hline
\end{tabular}

\footnotetext{
${ }^{1}$ measures the adequacy of the sampling and whether the matrix is an identity matrix.
}

\subsection{Exploratory factor analysis}

We note that the $\mathrm{KMO}^{1}$ index of the independent variable, which is made up of three components, namely : organizational and technological innovation, and medical innovation displays values that respect the selected threshold $(0.5)$. These different values are respectively as follows: $0.616 ; 0.709 ; 0.670$. On the other hand, Bartlett's test displays a significant value close to 0 which makes it possible to reject the null hypothesis claiming that all the correlations are not significant [29], [30].

Concerning the quality of representation of the items, the latter display commonalities greater than 0.5 (threshold selected is 0.4 ), which attests to a good quality of representation, especially since all the factor contributions are significant because they exceed 0.5 .

The clean measurement scales of "Organizational innovation" ; "Technological innovation" ; "Medical innovation" have respectively a very satisfactory Cronbach's Alpha value of $0.719 ; 0.746 ; 0.764$ which demonstrates the reliability of the measurement scale.

We note that the KMO index of the dependent variable, which is made up of three components, namely: durability, efficiency, and quality displays values which respect the selected threshold $(0.5)$. These different values are respectively as follows: $0.727 ; 0.680 ; 0.697$. Also, Bartlett's test displays a significant value close to 0 which makes it possible to reject the null hypothesis claiming that all the correlations are not significant. Table 4 summarizes the exploratory factor analysis of the three dimensions of the independent variables.

About the quality of representation of the items, the latter display commonalities greater than 0.5 (threshold selected is 0.4 ), which attests to a good quality of representation, especially since all the factor contributions are significant because they exceed 0.5 .

The clean measurement scales of "Sustainability"; "Efficiency"; "Quality" respectively have a very satisfactory Cronbach's Alpha of $0.910 ; 0.895 ; 0.821$ which demonstrates the reliability of the measurement scale. Table 5 summarizes the exploratory factor analysis of the three dimensions of the dependent variables.

Table 4: Summary of the exploratory factor analysis of the independent variable

\begin{tabular}{|c|c|c|}
\hline Independent variable & \multicolumn{2}{|c|}{ Organizational innovation } \\
\hline \multirow{3}{*}{ Quality of representation } & OI_1 &, 870 \\
\cline { 2 - 3 } & OI_2 &, 731 \\
\cline { 2 - 3 } & OI_3 &, 895 \\
\cline { 2 - 3 } & OI_4 &, 765 \\
\hline $\begin{array}{c}\text { KMO } \\
\text { Test }\end{array}$ & \multicolumn{2}{|c}{616} \\
\hline $\begin{array}{c}\text { Bartlett's } \\
\text { Sphericity test }\end{array}$ & Approximate chi- \\
square & 190,041 \\
\hline
\end{tabular}


A. Ouddasser et al. / Advances in Science, Technology and Engineering Systems Journal Vol. 6, No. 3, 277-285 (2021)

\begin{tabular}{|c|c|c|}
\hline & Signification &, 000 \\
\hline Cronbach's alpha & \multicolumn{2}{|c|}{, 719} \\
\hline Independent variable & \multicolumn{2}{|c|}{ Technological innovation } \\
\hline \multirow{4}{*}{ Quality of representation } & TI_1 &, 664 \\
\hline & TI 2 & ,478 \\
\hline & TI 3 &, 747 \\
\hline & TI 4 & 415 \\
\hline $\begin{array}{c}\text { KMO } \\
\text { Test }\end{array}$ & \multicolumn{2}{|l|}{,709 } \\
\hline \multirow[t]{2}{*}{$\begin{array}{c}\text { Bartlett's } \\
\text { Sphericity test }\end{array}$} & $\begin{array}{c}\text { Approximate chi- } \\
\text { square }\end{array}$ & 173,227 \\
\hline & Signification &, 000 \\
\hline Cronbach's alpha & \multicolumn{2}{|c|}{, 746} \\
\hline Independent variable & \multicolumn{2}{|c|}{ Medical innovation } \\
\hline \multirow{4}{*}{ Quality of representation } & MI 1 & ,649 \\
\hline & MI 2 &, 552 \\
\hline & MI_3 &, 460 \\
\hline & MI 4 &, 709 \\
\hline $\begin{array}{c}\text { KMO } \\
\text { Test }\end{array}$ & \multicolumn{2}{|l|}{670} \\
\hline \multirow[t]{2}{*}{$\begin{array}{c}\text { Bartlett's } \\
\text { Sphericity test }\end{array}$} & $\begin{array}{c}\text { Approximate chi- } \\
\text { square }\end{array}$ & 206,269 \\
\hline & Signification &, 000 \\
\hline Cronbach's alpha & \multicolumn{2}{|l|}{, 764} \\
\hline
\end{tabular}

\begin{tabular}{|c|c|c|}
\hline \multirow{2}{*}{$\begin{array}{c}\text { Bartlett's } \\
\text { Sphericity test }\end{array}$} & $\begin{array}{c}\text { Approximate chi- } \\
\text { square }\end{array}$ & 332,887 \\
\hline & Signification &, 000 \\
\hline Cronbach's alpha & \multicolumn{2}{|l|}{, 895} \\
\hline Dependent variable & \multicolumn{2}{|c|}{ Quality } \\
\hline \multirow{3}{*}{ Quality of representation } & QUAL_1 &, 802 \\
\hline & QUAL_2 & ,693 \\
\hline & QUAL 3 &, 719 \\
\hline $\begin{array}{c}\text { KMO } \\
\text { Test }\end{array}$ & \multicolumn{2}{|l|}{,697 } \\
\hline \multirow[t]{2}{*}{$\begin{array}{c}\text { Bartlett's } \\
\text { Sphericity test }\end{array}$} & $\begin{array}{c}\text { Approximate chi- } \\
\text { square }\end{array}$ & 183,674 \\
\hline & Signification &, 000 \\
\hline Cronbach's alpha & \multicolumn{2}{|l|}{, 821} \\
\hline
\end{tabular}

\subsection{Confirmatory factor analysis}

\section{Organizational innovation}

The first confirmatory analysis with the four items of the "organizational innovation" variable shows unsatisfactory results on some criteria retained. First, the factorial contribution of items OI_1, OI_4 is less than 0.6, which shows that the AVE2 and CR3 are below the threshold used [31], [32].

To this end, we decided to delete these two items and to relaunch a second confirmatory factor analysis with the remaining items [33].

From the second confirmatory analysis, we find that the results are very satisfactory for all the criteria, this variable meets all the required conditions. Indeed, the composite reliability index $(\mathrm{CR})$ is $0.817(>0.6)$ based on the work of [34];[35]. While the factorial contributions of the two items OI _, OI _ 3 largely exceed the threshold we have used $(>0.6)$. For the extracted mean-variance $(\mathrm{AVE})$ is greater than $0.5(\mathrm{AVE}=0.695)$ therefore the convergent validity is checked.

Regarding the discriminant validity, table $\mathrm{n}^{\circ} 10$ shows that the conditions for verifying the discriminant validity are satisfied.

Table 6 below shows us that the variable "Organizational innovation" is reliable and valid.

Table 6: Test of composite reliability and validity of Organizational innovation

\begin{tabular}{|c|c|c|c|c|c|}
\hline \multirow[t]{2}{*}{ Variable } & \multirow[t]{2}{*}{ Items } & \multicolumn{2}{|c|}{ Loadings } & $\mathrm{CR}$ & AVE \\
\hline & & $\begin{array}{c}\text { Before } \\
\text { elimination }\end{array}$ & $\begin{array}{c}\text { After } \\
\text { elimination }\end{array}$ & \multirow{5}{*}{0.817} & \multirow{5}{*}{0.695} \\
\hline \multirow{4}{*}{$\mathrm{OI}$} & OI_1 & $-0,458$ & - & & \\
\hline & OI 2 & 0,377 & 0,708 & & \\
\hline & OI 3 & 0,871 & 0,943 & & \\
\hline & OI_ 4 & 0,144 & - & & \\
\hline
\end{tabular}

${ }^{3}$ Composite reliability (CR) is a measure of internal consistency in scale 


\section{Technological innovation}

The first confirmatory analysis with the four items of the "technological innovation" variable shows unsatisfactory results on some criteria retained. First, the factorial contribution of item TI_4 is less than 0.6, which shows that the AVE and CR are below the selected threshold.

To this end, we decided to delete these two items and relaunch a second confirmatory factor analysis with the remaining items.

From the second confirmatory analysis, we find that the results are very satisfactory for all the criteria, this variable meets all the required conditions. Indeed, the Composite Reliability Index (CR) is $0.829(>0.6)$. While the factorial contributions of the three items TI_1, TI_2, TI_3 largely exceed the threshold we have used $(>0.6)$. For the extracted mean-variance (AVE) is greater than $0.5(\mathrm{AVE}=0.622)$ therefore the convergent validity is checked.

Regarding the discriminant validity, table $n^{\circ} 10$ shows that the conditions for verifying the discriminant validity are satisfied.

Table 7 below shows us that the "Technological innovation" variable is reliable and valid.

Table 7: Test of composite reliability and validity of Technological innovation

\begin{tabular}{|c|c|c|c|c|c|}
\hline \multirow{2}{*}{ Variable } & \multirow{2}{*}{ Items } & \multicolumn{2}{|c|}{ Loadings } & \multirow{2}{*}{ CR } & \multirow{2}{*}{ AVE } \\
\cline { 3 - 4 } & & $\begin{array}{c}\text { Before } \\
\text { elimination }\end{array}$ & $\begin{array}{c}\text { After } \\
\text { elimination }\end{array}$ & & \\
\hline \multirow{4}{*}{ TI } & TI_1 & 0,843 & 0,848 & \multirow{2}{*}{0.829} & \multirow{2}{*}{0.622} \\
\cline { 2 - 4 } & TI_2 & 0,864 & 0,867 & & \\
\cline { 2 - 4 } & TI_3 & 0,628 & 0,630 & & \\
\cline { 2 - 4 } & TI_4 & 0,233 & - & & \\
\hline
\end{tabular}

\section{Medical innovation}

The first confirmatory analysis with the four items of the "medical innovation" variable shows unsatisfactory results on some criteria retained. First, the factorial contribution of item MI_1 is less than 0.6, which shows that the AVE and CR are below the selected threshold.

To this end, we decided to delete these two items and relaunch a second confirmatory factor analysis with the remaining items.

From the second confirmatory analysis, we find that the results are very satisfactory for all the criteria, this variable meets all the required conditions. Indeed, the composite reliability index (CR) is $0.838(>0.6)$. While the factorial contributions of the three items MI_2, MI_3, MI_4 largely exceed the threshold we have used $(>0.6)$. For the extracted mean-variance (AVE) is greater than $0.5(\mathrm{AVE}=0.638)$ therefore the convergent validity is checked.

Regarding the discriminant validity, table $n^{\circ} 10$ shows that the conditions for verifying the discriminant validity are satisfied. Table 8 below shows us that the "Medical innovation" variable is reliable and valid.
Table 8: Test of composite reliability and validity of Medical innovation

\begin{tabular}{|c|c|c|c|c|c|}
\hline \multirow{2}{*}{ Variable } & \multirow{2}{*}{ Items } & \multicolumn{2}{|c|}{ Loadings } & $\mathrm{CR}$ & AVE \\
\hline & & $\begin{array}{c}\text { Before } \\
\text { elimination }\end{array}$ & $\begin{array}{c}\text { After } \\
\text { elimination }\end{array}$ & \multirow{5}{*}{0.838} & \multirow{5}{*}{0.638} \\
\hline \multirow{4}{*}{ MI } & MI_1 & 0,342 & - & & \\
\hline & MI 2 & 0,783 & 0,839 & & \\
\hline & MI_3 & 0,906 & 0,895 & & \\
\hline & MI_4 & 0,689 & 0,639 & & \\
\hline
\end{tabular}

\section{Organizational performance}

The first confirmatory analysis with the four items of the "organizational performance" variable shows satisfactory results on all the criteria retained. First, the factorial contribution of all the items is greater than 0.6, which shows that the AVE and CR are greater than the threshold used and represent 0.725 and 0.929 respectively.

Regarding the discriminant validity, table $n^{\circ} 10$ shows that the conditions for verifying the discriminant validity are satisfied.

Table 9 below shows us that the "Organizational performance" variable is reliable and valid.

Table 9: Test of composite reliability and validity of Organizational performance

\begin{tabular}{|c|c|c|c|c|}
\hline \multirow{2}{*}{ Variable } & Items & \multirow{2}{*}{ Loadings } & \multirow{2}{*}{ AVE } \\
& & & & \\
& & & \multirow{2}{*}{$\mathbf{0 . 9 2 9}$} & \multirow{2}{*}{$\mathbf{0 . 7 2 5}$} \\
OP & OP_1 & 0,676 & & \\
\cline { 2 - 3 } & OP_2 & 0,898 & & \\
\cline { 2 - 3 } & OP 3 & 0,871 & & \\
\cline { 2 - 3 } & OP 4 & 0,938 & & \\
\cline { 2 - 3 } & OP 5 & 0,863 & & \\
\hline
\end{tabular}

Discriminant validity of variables

Table 10: Discriminant validity of variables

\begin{tabular}{|l|c|c|c|c|}
\cline { 2 - 5 } \multicolumn{1}{c|}{} & MI & OI & TI & OP \\
\hline MI & $\mathbf{0 . 7 9 8}$ & & & \\
\hline OI & -0.054 & $\mathbf{0 . 8 3 4}$ & & \\
\hline TI & 0.884 & -0.121 & $\mathbf{0 . 7 8 9}$ & \\
\hline OP & 0.121 & -0.301 & 0.139 & $\mathbf{0 . 8 5 2}$ \\
\hline
\end{tabular}

Testing research hypotheses and discussing the results

After having analyzed all the tests, we now move on to a major step that of testing the hypotheses as well as the discussion of all the results obtained.

As part of this modest work, we have relied on testing three hypotheses constituting the object of our research. These different assumptions make it possible to link all the variables of our model, 
in particular, the independent variable "innovation", the dependent variable "organizational performance".

The calculation of the "P-Value" constitutes a fundamental step in our research work, moreover, a value of P-Value which does not exceed $5 \%(\mathrm{P} \leq 0.05)$ means that the hypothesis is acceptable. Otherwise, where the P-value exceeds 5\% ( $>>0.05)$ means that the hypothesis is rejected. This test is performed based on the $\mathrm{T}$ - value (the value associated with the student test).

In this context, two hypotheses were rejected because they have a p-value that exceeds the threshold of 5\%. So that the third hypothesis, that of the impact of organizational innovation on organizational performance, has been accepted because it has a pvalue of less than $5 \%$.

Table 11 shows all the relationships between independent and dependent variables.

Table 11: Research hypothesis test result

\begin{tabular}{|c|c|c|c|c|c|l|}
\cline { 2 - 7 } \multicolumn{1}{c|}{} & $\begin{array}{c}\text { Initial } \\
\text { sample } \\
(\mathbf{O})\end{array}$ & $\begin{array}{c}\text { Sample } \\
\text { mean } \\
(\mathbf{M})\end{array}$ & $\begin{array}{c}\text { Standard } \\
\text { deviation } \\
\text { (STDEV) }\end{array}$ & $\begin{array}{c}\text { T value }(\mathbf{1} \\
\text { O / } \\
\text { STDEV } \mid)\end{array}$ & $\begin{array}{c}\text { P- } \\
\text { values }\end{array}$ & Decision \\
\hline $\begin{array}{c}\mathrm{MI} \rightarrow \\
\text { OP }\end{array}$ & 0.063 & 0.092 & 0.244 & 0.258 & 0.797 & Rejected \\
\hline $\begin{array}{c}\text { OI } \rightarrow \\
\text { OP }\end{array}$ & -0.291 & -0.303 & 0.075 & 3.895 & 0.000 & Accepted \\
\hline $\begin{array}{c}\text { TI } \rightarrow \\
\text { OP }\end{array}$ & 0.048 & 0.035 & 0.245 & 0.198 & 0.843 & Rejected \\
\hline
\end{tabular}

\subsection{Discussion of results}

\section{Hypothesis $n{ }^{\circ} 1$}

First, we find that the construct "Organizational innovation" has a significant effect on "Organizational performance". Indeed, this construct positively influences organizational performance within the healthcare facility with a P-value of 0.000 .

The results obtained at the Hassan II University Hospital Center - Fez in Morocco show a positive relationship between organizational innovation and organizational performance. In this context, we underline that the contribution of organizational innovation or innovation in its intangible form impacts and influences the performance of organizations, and therefore, this indicates that the implementation of innovation processes allowing reorganizing the way organizations operate is essential for the sustainability of their activities, and a very attractive overall quality. Following our review of the literature, we can underline that this relationship is recommended by various authors such as [20].

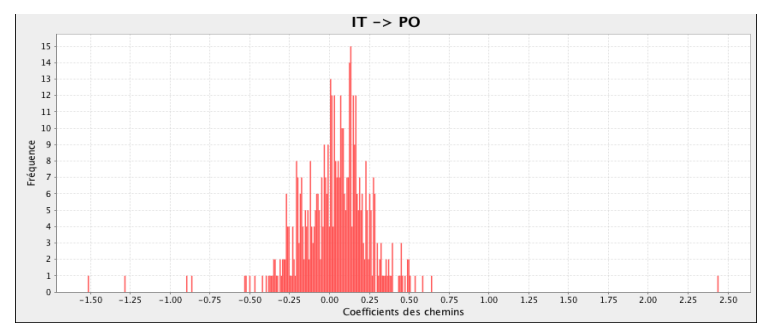

Figure 1 : The main relationships of the variables used in our model (OI --> OP)
Organizational innovation remains a necessity for the prosperity and growth of every healthcare establishment. Also, it is the bedrock of success for all other types of innovation. See the Figure 1 of hypothesis 1 .

Therefore, hypothesis (H.1) is validated.

\section{Hypothesis $n{ }^{\circ} 2$}

Second, we find that the construct "Technological innovation" has no significant effect on "Organizational performance". However, this construct negatively influences organizational performance within the healthcare facility with a P-value of 0.843 .

Although technological innovation is theoretically essential to increase performance, field practice conceals that it does not have this influencing weight and therefore remains dependent on the context, culture, and values of each organization or establishment.

From the results obtained at the Hassan II University Hospital Center - Fez in Morocco, we note that technological innovation does not influence the relationship with organizational performance. That said, the enrollment of the health establishment towards the technology path strongly depends on investing previously in human resources including periodic training, apprenticeship, and improving working conditions. These various parameters are essential, and will lead to profound changes in the level of appropriation and dissemination of technological innovation. See the Figure 2 of hypothesis 2.

Therefore, the hypothesis (H.2) is not validated.

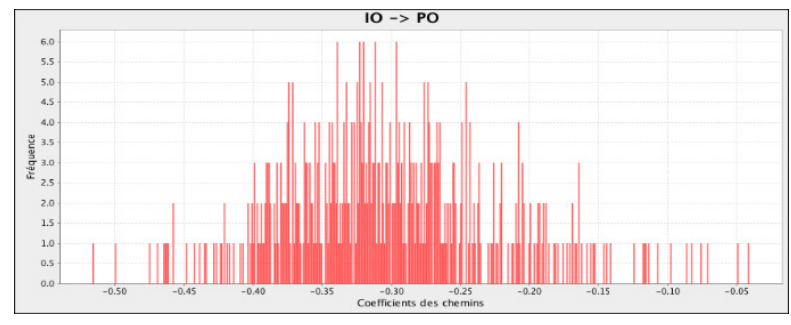

Figure 2: The main relationships of the variables used in our model (TI --> OP)

\section{Hypothesis n ${ }^{\circ} 3$}

Third, we find that the construct "medical innovation" has no significant effect on "organizational performance". However, this construct negatively influences Organizational performance within the healthcare facility with a P-value of 0.797.

According to the results obtained at the Hassan II University Hospital Center - Fez in Morocco, it should be noted that medical innovation is necessary to improve treatment protocols and better manage drug stocks. Despite its importance, this relationship is not significant within the Center Hospital Hassan II - Fez, because, according to the recommendations of health professionals, the health sector must be strongly involved in the establishment of all the mechanisms thus making it possible to make medical innovation relevant in the medium, and long term.

Despite the proven importance of medical innovation in improving treatment protocols, the reality of practice sometimes stems from constraints that slow down the achievement of this 
end. These constraints are often linked to a lack of organizational agility of the establishment and the non-involvement of medical human resources in the path of innovative medicalization which requires much more investment in medical research. See the Figure 3 of hypothesis 3 .

Therefore, the hypothesis (H.3) is not validated.

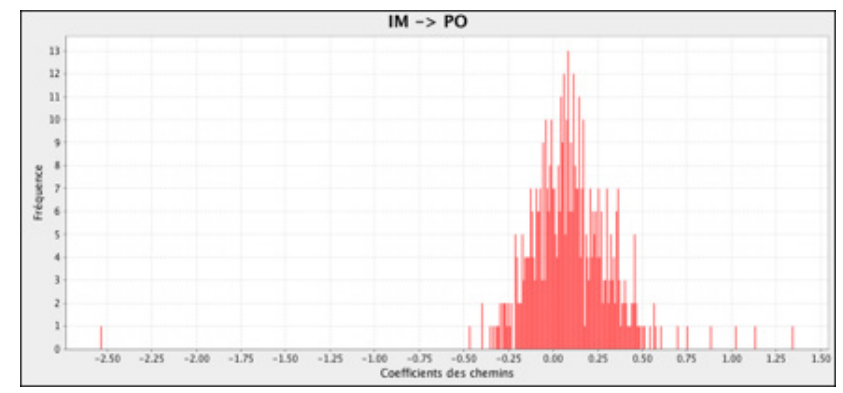

Figure 3 : The main relationships of the variables used in our model (MI --> OP)

\section{Conclusions}

This present paper has tried to study the place that innovation can occupy with its various forms in the increase of organizational performance within health establishments. As a result, it emerges that innovation is a multidimensional notion that allows the health sector to seize opportunities to take into account measures for each context.

For the case of our research, we conducted a study on the contribution of organizational, technological, and medical innovations in improving the organizational performance of the Hassan II University Hospital Center - Fez, therefore, three hypotheses were tested based on exploratory factor analysis and confirmatory factor analysis. According to the results obtained, two hypotheses were rejected, those of technological innovation, and medical innovation, while the third hypothesis of the impact of organizational innovation was retained, which shows that this third form intangible is considered the basis of all form of innovation.

Moreover, for the Moroccan context, if hospitals tend to change, we will have to tackle this new paradigm now, based on international experiences. It is therefore essential to achieve this new logic without the involvement of all the stakeholders who exercise a crucial influence on the conduct of activities. In this regard, organizational, technological, and medical innovation today appear to be determining factors whose main mission is to achieve true hospital performance.

\section{References}

[1] G. Haberler, “Joseph Alois Schumpeter 1883-1950," The Quarterly Journal of Economics, 64(3), 333-372, 1950

[2] E.M. Castro, T. Van Regenmortel, K. Vanhaecht, W. Sermeus, A. Van Hecke, "Patient empowerment, patient participation and patientcenteredness in hospital care: a concept analysis based on a literature review," Patient Education and Counseling, 99(12), 1923-1939, 2016.

[3] M. Hees, "Changements et résistances," Perspective Soignante, (7), 52-62, 2000.

[4] M. Dodgson, S. Hinze, "Indicators used to measure the innovation process: defects and possible remedies," Research Evaluation, 9(2), 101-114, 2000.

[5] J. Hartley, "Innovation in governance and public services: Past and present," Public Money and Management, 25(1), 27-34, 2005.

[6] J. Haderlein, "Unleashing the untapped potential of hospital philanthropy," Health Affairs, 25(2), 541-545, 2006
[7] H.E. Klarman, "Role of philanthropy in hospitals," American Journal of Public Health and the Nations Health, 52(8), 1227-1237, 1962.

[8] A.U. Akeel, D. Mundy, "Re-thinking technology and its growing role in enabling patient empowerment," Health Informatics Journal, 25(4), 1278$1289,2019$.

[9] P. McCann, R. Ortega-Argilés, "Modern regional innovation policy," Cambridge Journal of Regions, Economy and Society, 6(2), 187-216, 2013.

[10] M. d'Oslo, "Principes directeurs proposés pour le recueil et l'interprétation des données sur l'innovation technologique," Paris: OCDE, 1997.

[11] G. Azar, F. Ciabuschi, "Organizational innovation, technological innovation, and export performance: The effects of innovation radicalness and extensiveness," International Business Review, 26(2), 324-336, 2017.

[12] B. Kelly, D. Papanikolaou, A. Seru, M. Taddy, Measuring technological innovation over the long run, National Bureau of Economic Research, 2018.

[13] J. Vacherand-Revel, M. Ianeva, J. Guibourdenche, J.-F. Carlotti, "Les pratiques du télétravail pendulaire de cadres : reconfiguration des écosystèmes relationnels et d'activités," Psychologie Du Travail et Des Organisations, 22(1), 54-73, 2016.

[14] C. Van den Bulte, G.L. Lilien, "Medical innovation revisited: Social contagion versus marketing effort," American Journal of Sociology, 106(5), $1409-1435,2001$.

[15] A.M. Petersen, D. Rotolo, L. Leydesdorff, "A triple helix model of medical innovation: Supply, demand, and technological capabilities in terms of Medical Subject Headings," Research Policy, 45(3), 666-681, 2016.

[16] V. Iacopino, D. Mascia, A. Cicchetti, "Professional networks and the alignment of individual perceptions about medical innovation," Health Care Management Review, 43(2), 92-103, 2018.

[17] J. Gardner, Rethinking the clinical gaze: Patient-centred innovation in paediatric neurology, Springer, 2017.

[18] T.A. Brown, Confirmatory factor analysis for applied research, Guilford publications, 2015.

[19] C. Martini, "Hypothetico-Deductive Method," The Wiley-Blackwell Encyclopedia of Social Theory, 1-3, 2017.

[20] J. Cloutier, Qu'est-ce que l'innovation sociale ?, Crises Montréal, 2003.

[21] E. Mercier-Laurent, "Innovation organisationnelle vue comme une composante de l'innovation globale," Journée de Recherche Crest-Magellan Innovation Organisationnelle, 28, 2008.

[22] S. Schrayer, Les technologies médicales : une industrie de la santé, Ed. Pradel, 1995.

[23] S.M. Shortell, C.L. Bennett, G.R. Byck, "Assessing the impact of continuous quality improvement on clinical practice: what it will take to accelerate progress," The Milbank Quarterly, 76(4), 593-624, 1998.

[24] J.E. Piña-Garza, G.D. Montouris, F. Vekeman, W.Y. Cheng, E. Tuttle, P. Giguere-Duval, M.S. Duh, V. Shen, T.B. Saurer, J. Isojarvi, “Assessment of treatment patterns and healthcare costs associated with probable LennoxGastaut syndrome," Epilepsy \& Behavior, 73, 46-50, 2017.

[25] C. Sicotte, F. Champagne, A.P. Contandriopoulos, J. Barnsley, F. Beland, S.G. Leggat, J.L. Denis, H. Bilodeau, A. Langley, M. Bremond, G.R. Baker, "A Conceptual Framework for the Analysis of Health Care Organizations' Performance," Health Services Management Research, 11(1), 24-41, 1998, doi:10.1177/095148489801100106.

[26] C. Sicotte, F. Champagne, A.-P. Contandriopoulos, C. TILQUIN, "La performance organisationnelle dans les organisations et les soins de santé," ruptures : Revue transdisciplinaire en sante, 6(1), 34-101, 1999.

[27] T. Parsons, The social system., Free Press, Glencoe, Ill., 1951.

[28] T. Parsons, Social systems and the evolution of action theory, Free Press, 1977.

[29] H.F. Kaiser, "An index of factorial simplicity," Psychometrika, 39(1), 3136, 1974.

[30] H.F. Kaiser, "Image and anti-image covariance matrices from a correlation matrix that may be singular.," 1976.

[31] J.F. Hair Jr, M. Sarstedt, L. Hopkins, V.G. Kuppelwieser, "Partial least squares structural equation modeling (PLS-SEM): An emerging tool in business research," European Business Review, 2014.

[32] J.F. Hair, J.J. Risher, M. Sarstedt, C.M. Ringle, "When to use and how to report the results of PLS-SEM," European Business Review, 2019.

[33] T.R. Levine, "Confirmatory factor analysis," The International Encyclopedia of Interpersonal Communication, 1-5, 2015.

[34] R.P. Bagozzi, Y. Yi, "On the evaluation of structural equation models," Journal of the Academy of Marketing Science, 16(1), 74-94, 1988.

[35] K. Wilson, E. Sandoz, J. Kitchens, M. Roberts, "The Valued Living Questionnaire: Defining and Measuring Valued Action within a Behavioral Framework," The Psychological Record, 60, 249-272, 2010 doi:10.1007/BF03395706. 